\title{
Healthy Living: Monitoring Your Blood Pressure at Home ${ }^{1}$
}

\author{
Linda B. Bobroff²
}

Do you think your blood pressure may be too high? Have you been diagnosed with high blood pressure (hypertension)? In either case, it is recommended that you monitor your blood pressure at home and get it checked at the doctor's office. This can help your doctor determine if you have high blood pressure and, if so, whether your treatment plan is working. Read on to learn how to monitor your blood pressure at home.

\section{How to Check}

The American Heart Association (AHA) recommends using an approved automatic, cuffstyle, upper-arm (bicep) monitor to check your blood pressure. Follow these AHA guidelines to ensure an accurate reading (AHA, 2016):

1. Make sure the cuff fits.

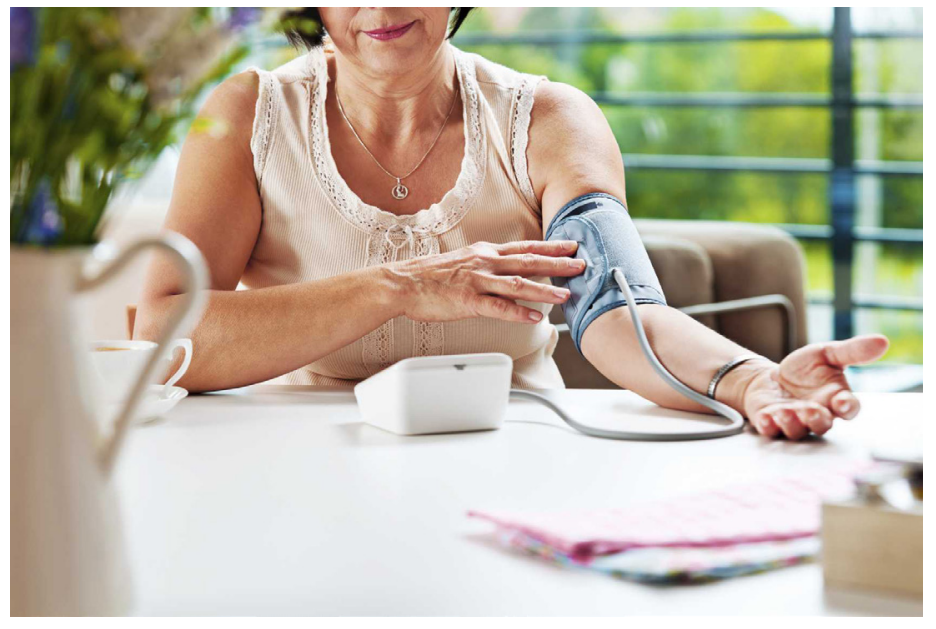

Credits: Izabela Habur/iStockphoto.com

2. Do not smoke, drink caffeinated beverages, or exercise within 30 minutes of measuring blood pressure.

3. Be still.

4. Sit with your back straight and supported.

5. Place your feet flat on the floor.

1. This document is FCS8882 (la versión en español de este documento es Vida saludable: Monitoreando la presión arterial desde la casa (FCS8882-Span)), one of a series of the Department of Family, Youth and Community Sciences, UF/IFAS Extension. Original publication date August 2008. Revised November 2018. Visit the EDIS website at https://edis.ifas.ufl.edu for the currently supported version of this publication.

2. Linda B. Bobroff, PhD, RDN, professor, Department of Family, Youth and Community Sciences; UF/IFAS Extension, Gainesville, FL 32611. 
6. Support your arm on a flat surface such as a table with your upper arm at heart level.

7. Wrap the cuff around your upper arm and check that the bottom of the cuff is placed where your arm bends.

8. Take two or three readings one minute apart and record all results.

9. Take readings at the same time each day.

\section{What do the numbers mean?}

You may notice that your blood pressure varies throughout the day. This is normal. This variation is why you should take your readings at the same time every day. The AHA has different categories for blood pressure to help you find out what your numbers mean (see Table 1).

Keep a log of your readings and take it to every doctor visit. This allows your doctor to keep track of your blood pressure and change your treatment plan if needed. Use the log on the last page (Table 2) and make copies as necessary.

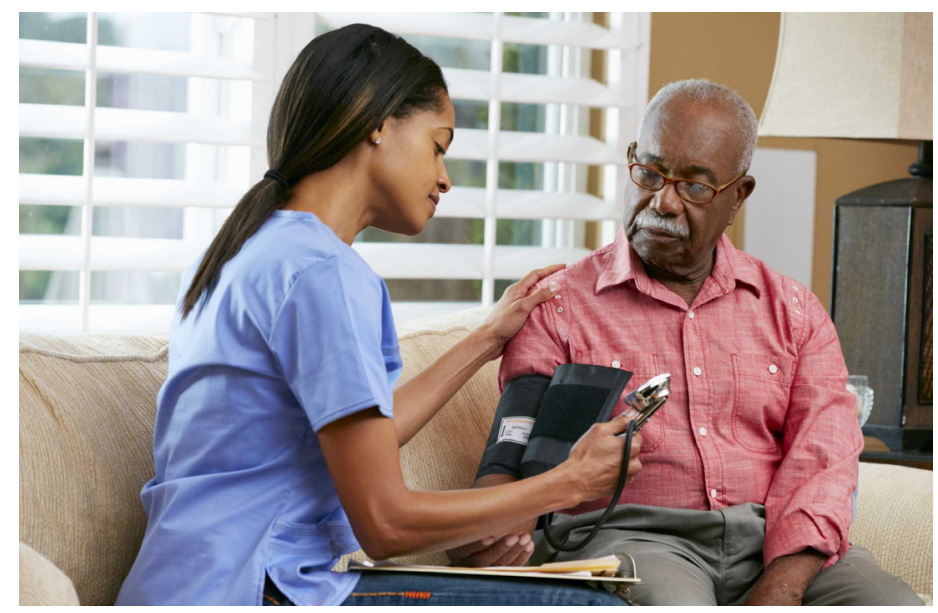

Credits: Thinkstock.com

\section{References}

American Heart Association. (2016). Monitoring your blood pressure at home. Accessed on October 25, 2018. http://www.heart.org/ HEARTORG/Conditions/HighBloodPressure/ SymptomsDiagnosisMonitoringofHighBloodPressure/Home-Blood-Pressure-Monitoring UCM_301874_Article.jsp

American Heart Association. (2017). Understanding blood pressure readings. Accessed on October 25, 2018. http://www.heart.org/ HEARTORG/Conditions/HighBloodPressure/GettheFactsAboutHighBloodPressure/ Understanding-Blood-Pressure-Readings_ UCM_301764_Article.jsp

Whelton, P. K., Carey, R. M., Aronow, W. S., Casey, D. E., Collins, K. J., Himmelfarb, C. D., ... Wright, J. T. (2017). 2017 ACC/AHA/ AAPA/ABC/ACPM/AGS/APhA/ASH/ASPC/ NMA/PCNA Guideline for the Prevention, Detection, Evaluation, and Management of High Blood Pressure in Adults: A Report of the American College of Cardiology/American Heart Association Task Force on Clinical Practice Guidelines. Hypertension, 71(6), 12691324. DOI: 10.1161/HYP.0000000000000066 
Table 1. Blood pressure categories from the American Heart Association.

\begin{tabular}{|c|c|c|c|}
\hline Category & $\begin{array}{l}\text { Systolic }{ }^{1} \\
(\mathrm{~mm} \mathrm{Hg})\end{array}$ & & $\begin{array}{c}\text { Diastolic }^{2} \\
(\mathrm{~mm} \mathrm{Hg})\end{array}$ \\
\hline Normal & $<120$ & and & $<80$ \\
\hline Elevated & $120-129$ & and & $<80$ \\
\hline \multicolumn{4}{|c|}{ High Blood Pressure } \\
\hline Stage 1 & $130-139$ & or & $80-89$ \\
\hline Stage 2 & $\geq 140$ & or & $\geq 90$ \\
\hline \multicolumn{4}{|c|}{$\begin{array}{l}1 \text { Systolic pressure is represented by the top number in your blood } \\
\text { pressure reading. This number is the higher of the two numbers and } \\
\text { measures pressure in your arteries when your heart beats, or during the } \\
\text { contraction of the heart muscle (AHA, 2017). } \\
{ }^{2} \text { Diastolic pressure is represented by the bottom number in your blood } \\
\text { pressure reading. This number is the lower of the two numbers and } \\
\text { measures the pressure in your arteries between heartbeats, or when the } \\
\text { heart muscle is at rest and the heart is refilling with blood (AHA, 2017). } \\
\text { Source: Whelton et al. (2017) }\end{array}$} \\
\hline
\end{tabular}


Table 2. Blood pressure log.

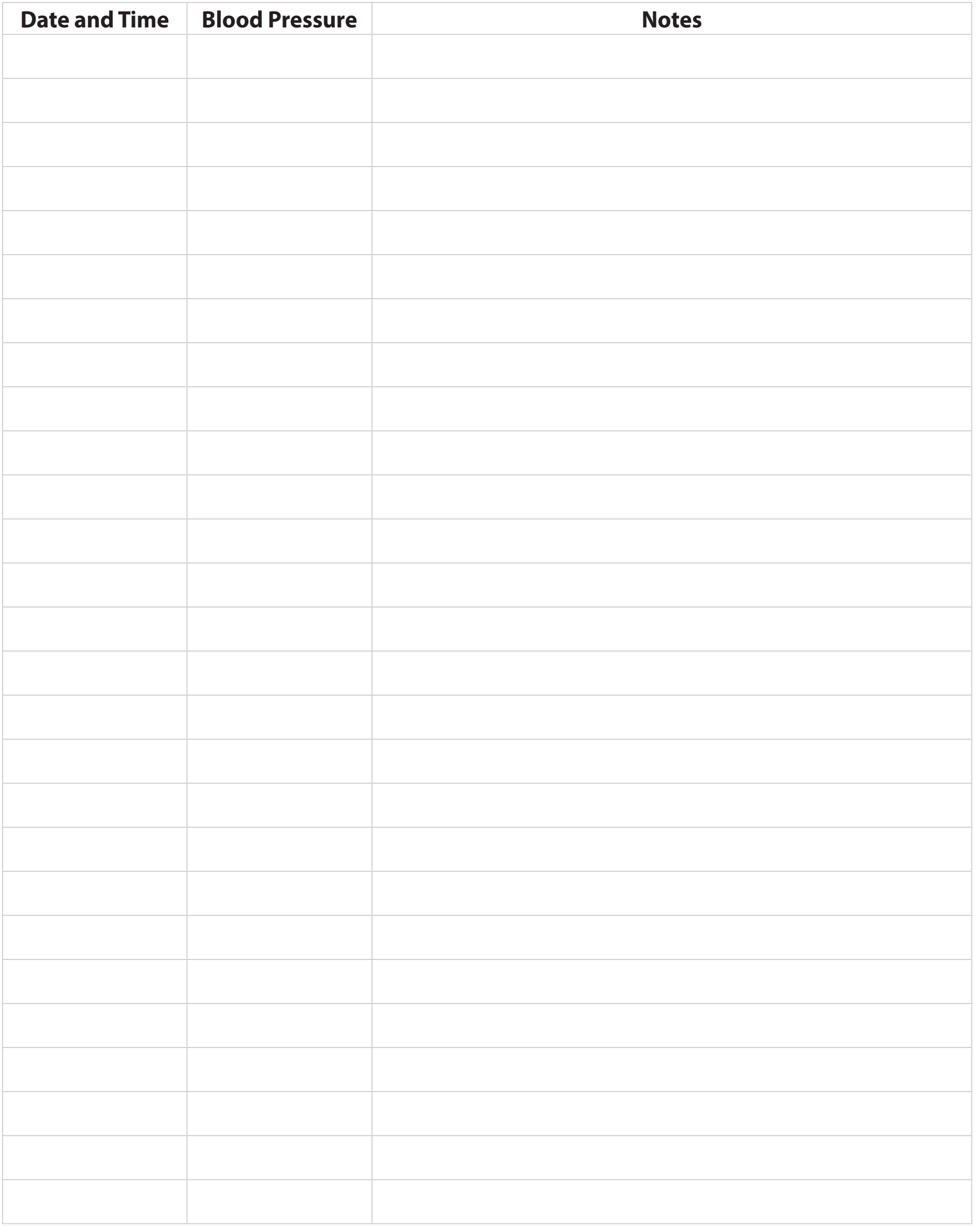

